\title{
DE GEBOUWEN VAN DEN LANDBOUW IN HET WETS- ONTWERP TOT HERZIENING VAN DE BELASTBARE OPBRENGST DER GEBOUWDE EIGENDOMMEN.
}

In het door den Minister van Financiën ingediende wetsontwerp tot herziening van de belastbare opbrengst der gebouwde eigendommen, treedt op den voorgrond het streven naar vaste grondslagen voor de bepaling dier opbrengst.

Waar mogelijk is der schattingcommissiën tot taak gesteld om door kennisneming van, onder normale omstandigheden gesloten, overeenkomsten de werkelijke huur- en koopprijzen te leeren kennen om zoo voor gewone woonhuizen en voor fabrieken en dergelijken, een grondslag te verkrijgen, niet vau persoonlijke opvatting afhankelijk.

Werkelijke huur- of koopprijzen zijn voor gebouwen tot hoeven behoorende van zelve als grondslag uitgesloten, omdat voor deze slechts bij hooge uitzondering verkoop of verhuur voorkomt, zonder dat daaronder de bijbehoorende gronden begrepen zijn.

Hier wordt getracht een vast uitgangspunt te erlangen, door de belastbare opbrengst af te leiden uit de stichtingskosten.

De bepaling echter dat hierbij zal worden in acht genomen de waardevermindering door achteruitgang van den toestand van het gebouw, opent een ruim veld voor versehil in opvatting van de met de schatting belaste commissiën en maakt dat voor de landelijke gebouwen het streven naar een vasten grondslag wel het minst tot zijn recht komt.

Tevens wordt in $\S 2$ der Memorie van Toelichting de bedoeling uitgesproken om de gegronde grieven te herstellen, 
welke tegen de aanslagcijfers der gebouwen tot hoeven behoorende, naar de wet van 22 Juli 1873 (Stbl. 116) bestaan.

Het doel van dezen arbeid is daarom na te gaan of het wetsontwerp geheel aan deze bedoeling beantwoordt en of zonder bezwaar, in de schatting niet meer gelijkmatigheid kan worden gebracht.

Herstel der grieven door herstel van den toestand vóór 1873, waarbij de schuren, stallen en werkplaatsen voor den landbouw geheel waren vrijgelaten en voor belasting alleen in aanmerking kwam dat deel der gebouwen, dat uitsluitend tot woning diende, ware ongetwijfeld meer afdoende, doch daargelaten dat het in het algemeen niet gemakkelijk is den kring van eenmaal belaste voorwerpen in te krimpen, komt een poging tot verkrijging van zulk herstel te minder doeltreffend voor, nu het betoog in de Memorie van Toelichting tot verdediging van de opheffing dier vrijstelling, in hoofdzaak juist te achten is,

Juist is voorzeker dat een groot deel der gronden door den landbouw gebruikt, niet te exploiteeren zoude zijn, wanneer er geene gebouwen bij behoorden en ook dat uit het niet in grooten getale sloopen van die gebouwen, voldoende blijkt dat zij voor de eigenars niet enkel lastposten zijn, zoodat wel degelijk een deel der pacht is te beschouwen als rente van het aan de gebouwen ten koste gelegde kapitaal.

Evenwel mag de beteekenis hiervan niet worden overschat, want ook dár blijven veelal gebouwen bestaan, waar zonder deze wèl gelegenheid tot verhuring van den grond zoude zijn.

Uit dit verschijnsel valt af te leiden dat het deel van de pacht uitmakende de rente van het bouwkapitaal, slechts klein kan zijn. De oorzaak er van is dat bij verhuring van een bedrijf in zijn geheel, met gebouwen en stallen, waarin voortdurend huisraad, vee, vruchten en werktuigen van den pachter aanwezig zijn, de waarborg roor richtige betaling der pachtpenningen, veel grooter is dan bij verhuring van zoogenaamde losse landerijen. De eigenaar getroost zich dus de lasten aan de gebouwen verbonden, ook ten deele als eene verzekeringspremie voor de ontrangst van de geheele rente. 
De hierdoor vermeden verliezen onder cijfers te brengen is nitteraard niet wel mogelijk, maar in het algemeen is ook met dezen factor rekening te houden.

Het uit de Memorie van Toelichting angehaalde betoog en de hierv6ór vermelde omstandigheid vinden nu bovendien nog verdere toepassing.

Omdat de gebouwen de exploitatie van den grond mogelijk maken en omdat zij tevens de betaling der opbrengst eenigermate waarborgen, kan ook zonder vrees voor tegenspraak worden beweerd dat de opbrengst van den grond zelf (d. w. z. de belastbare en belaste opbrengst) reeds voor een deel gevolg is van het bestaan der gebouwen en dat het dus niet billijk is deze voor zich zelf op nieuw te treffen, tenzij voor dat deel hunner waarde dat niet geacht kan worden in de vermeerderde opbrengst van den grond begrepen te zijn.

In elk geval blijkt er uit dat een aanslag van tot hoeven behoorende gebouwen, tot slechts een klein gedeelte van dien van andere gebouwen van overigens gelijke stichtingskosten, ten volle gerechtvaardigd is en blijft nog slechts de bepaling van het percentsgewijze bedrag over.

In de Memorie van Toelichting wordt de pacht beschouwd als rente van het geheele kapitaal gestoken in land en gebouwen en dan, ter vermijding van een hoog cijfer, $3 !$ pCt. van de waarde der gebouwen als belastbare opbrengst aangenomen.

Indien het kapitaal op deze wijze omschreven wordt, is het nog niet zoo zeker of $3 \frac{1}{2}$ pCt. niet eerder hoog te noemen is, maar ook al ware dat anders, dan nog blijkt uit het voorgaande dat voor deze gebouwen slechts een deel daarvan mag worden genomen.

Beschouwingen outrent het aandeel dat in het landbouwbedrijf aan de gebouwen toekomt, zouden onnoodig zijn en de moeilijkheden aan de bepaling er van verbonden zouden dus vervallen, wanneer, zooals bij de in 1893 ingediende wet de Minister Pierson voorstelde, het landbouwbedrijf in zijn geheel, als belastingobject werd beschouwd.

Onvermijdelijk ware echter daarbij (zooals dan ook toen werd 
voorgesteld) gelijktijdige herziening van de belastbare opbrengst der ongebouwde eigendommen, althans voor zoover bij hoeven in gebruik, omdat anders de tegenwoordige pachten veminderd met de thans geldende belastbare opbrengsten, al bitter weinig ter belasting der gebonwen zouden blijken over te laten.

Nadere uitwerking van dit denkbeeld kan echter slechts geringe praktische waarde hebben, nu de tegenwoordige regeering den tijd voor eene herziening van de belastbare opbrengst der ongebouwde eigendommen nog niet gekomen acht en het schijnt van meer belang om aan de hand van het wetsvoorstel te onderzoeken of werkelijk voor de landelijke gebouwen ontlasting te verwachten is.

De belastbare opbrengst van woonhuizen wordt volgens het voorstel bepaald op den werkelijken huurprijs, die van fabrieken en dergelijke op 6 pCt. van de werkelijke koopwaarde en het is daarom mogelijk dat ook zonder vermindering van de belastbare opbrengst der landelijke gebouwen, deze door verschuiving van belasting zouden worden ontlast, maar bij gebrek aan algemeene en zeer uitvoerige gegevens, kan dit hier niet beoordeeld worden en groot zal deze invloed warsehijnlijk niet zijn, daar de Minister, blijkens $\S 4$ der Memorie van Toelichting, geen aanzienlijke verhooging van het totaal der belastbare opbrengst verwacht.

Voor dit onderzoek nu wordt uitgegaan van de bestaande aanslagen voor de belastbare opbrengst van eene reeks van gebouwen tot 98 hoeven behoorende, gelegen in Noordbrabant en Zeeland, bijeengebracht in de 3 ondervolgende tabellen.

Deze bevatten:

$1^{\circ}$ de grootte der geheele hoeve,

$2^{\circ}$ de stichtingskosten der bestaande gebouwen afgeleid uit de bedragen warvoor zij tegen brandschade verzekerd zijn '). $3^{\circ}$ de belastbare opbrengst "gebouwd" van de tot elke hoeve behoorende gebouwen,

$4^{\circ}$ de belastbare opbrengst "ongebouwd" van de tot de hoeve behoorende gronden (voor zoover beschikbaar).

1) $\mathrm{Bij}$ verzekering in herbouw, is het verzekerde bedrag verhoogd met $15 \mathrm{pCt}$. De volle vermeerdering met $25 \mathrm{pCt}$. (art. 289 W. v. K.) kwam om bekende redenen te hoog voor. 


\section{1}

De hoeven zijn gesplitst in 3 rubrieken :

A. op kleigrond, B. op zavelgrond en goeden zandgrond, C. op zandgrond.

In de tabellen zijn opgenomen alle verkregen gegevens, zonder eenige keuze of sorteering zoodat, waar het aantal uit een oogpunt van statistiek wel niet groot is, toch groote waarschijnlijkheid bestaat, dat uitbreiding van dat aantal, voor de betrokken streken geene groote fouten zoude aantoonen.

Alleen werden weggelaten enkele hoeven, welke het gebruik of het medegebruik hadden van meer dan gewone oppervlakten schorgrond of dijken, plaggenheide of bosch.

Omtrent alle gebouwen bestaat zekerheid dat zij zoowel thans als tijdens de laatste schatting in goeden of zeer voldoenden staat van onderhoud verkeeren. 
112

A. Hoeven op Kleigrond (polders).

\begin{tabular}{|c|c|c|c|c|}
\hline \multirow{2}{*}{$\begin{array}{c}\text { Grootte } \\
\text { der hoeve. } \\
\text { H. a. }\end{array}$} & \multirow{2}{*}{$\begin{array}{c}\text { Stichtings- } \\
\text { waarde der } \\
\text { gebouwen. } \\
f\end{array}$} & \multicolumn{2}{|c|}{ BELASTBARE OPBRENGST } & \multirow{2}{*}{ Toelichting. } \\
\hline & & $\begin{array}{c}\text { Gebouwd. } \\
f\end{array}$ & $\begin{array}{c}\text { Ongebouwd. } \\
f\end{array}$ & \\
\hline 73 & 19200 & 600 & - & \multirow{29}{*}{$\begin{array}{l}\text { Gemeenten: Steen- } \\
\text { bergen, Werken- } \\
\text { dam, Dinteloord, } \\
\text { Colijnsplaat, Cats, } \\
\text { 's Gravenpolder en } \\
\text { Hontenisse. }\end{array}$} \\
\hline 67 & 16900 & 250 & - & \\
\hline 58 & 16700 & 275 & - & \\
\hline 52 & 16100 & 325 & 3470 & \\
\hline 47 & 16050 & 325 & - & \\
\hline 74 & 15400 & 325 & - & \\
\hline 60 & 15400 & 325 & 4421 & \\
\hline 66 & 15100 & 405 & 3340 & \\
\hline 51 & 15000 & 325 & 2401 & \\
\hline 51 & 14800 & 275 & 3814 & \\
\hline 64 & 14650 & 275 & 4688 & \\
\hline 68 & 14550 & 325 & 4296 & \\
\hline 62 & 141.00 & 160 & - & \\
\hline 49 & 13800 & 300 & 3207 & \\
\hline 53 & 13800 & 275 & 3857 & \\
\hline 50 & 13800 & 275 & 2290 & \\
\hline 52 & 13700 & 250 & 3471 & \\
\hline $5 ?$ & 13350 & 250 & 3528 & \\
\hline 53 & 13200 & 300 & 4064 & \\
\hline 38 & 12400 & 325 & 1914 & \\
\hline 37 & 12300 & 225 & 2620 & \\
\hline 64 & 11700 & 330 & - & \\
\hline 75 & 11400 & 150 & - & \\
\hline 48 & 11200 & 325 & 2370 & \\
\hline 71 & 10000 & 150 & - & \\
\hline 49 & 9600 & 280 & - & \\
\hline 56 & 9550 & 325 & - & \\
\hline 1540 & 373750 & 7950 & 53751 & \\
\hline Gemidd. 5 & 13880 & 294 & - & \\
\hline
\end{tabular}




\section{3}

B. Hoeven op Zavel- en goede Zandgronden.

\begin{tabular}{|c|c|c|c|c|}
\hline \multirow{2}{*}{$\begin{array}{c}\text { Grootte } \\
\text { der hoeve. } \\
\text { H. a. }\end{array}$} & \multirow{2}{*}{$\begin{array}{l}\text { Stichtings- } \\
\text { waarde der } \\
\text { gebouwen. } \\
f\end{array}$} & \multicolumn{2}{|c|}{ BELASTBARE OPBRENGST. } & \multirow{2}{*}{ Toelichting. } \\
\hline & & $\begin{array}{c}\text { Gebouwd. } \\
f\end{array}$ & $\begin{array}{c}\text { Ongebouwd } \\
f\end{array}$ & \\
\hline 14 & 7550 & 90 & 308 & Gemeenten: Baard- \\
\hline 13 & 7200 & 130 & 409 & wijk, Cuijk, Din- \\
\hline 10 & 7050 & 110 & 250 & ther, Etten, Gastel \\
\hline 11 & 6850 & 140 & 359 & St. Michiels-Gestel, \\
\hline 10 & 6300 & 80 & 192 & Hilvarenbeek, Hel- \\
\hline 21 & 6150 & 160 & 575 & voirt, Rijsbergen, \\
\hline 30 & 6050 & 120 & - & Schijndel en Vier- \\
\hline 30 & 6050 & 90 & - & lingsbeek. \\
\hline 21 & 6050 & 80 & 339 & \\
\hline 9 & 5950 & 120 & 238 & \\
\hline 9 & 5750 & 110 & 260 & \\
\hline 13 & 5700 & 90 & 407 & \\
\hline 11 & 5600 & 110 & 320 & \\
\hline 13 & 5350 & 195 & 406 & \\
\hline 13 & 5350 & 140 & 563 & \\
\hline 12 & 5250 & 200 & 222 & \\
\hline 11 & 5150 & 100 & 289 & \\
\hline 10 & 5050 & 50 & 188 & \\
\hline 6 & 4950 & 100 & 182 & \\
\hline 22 & 4400 & 80 & - & \\
\hline 10 & 4350 & 120 & 421 & \\
\hline 8 & 4000 & 70 & 196 & \\
\hline 8 & 3900 & 60 & 241 & \\
\hline 10 & 3300 & 80 & 557 & \\
\hline 6 & 3200 & 80 & 270 & \\
\hline 5 & 2750 & 55 & 265 & \\
\hline 5 & 2700 & 80 & 265 & \\
\hline 7 & 2650 & 70 & 253 & \\
\hline 9 & 2300 & 50 & 349 & \\
\hline 357 & 146900 & 2960 & $8 \mathbf{3 2 4}$ & \\
\hline gemida. 12 & 5065 & 102 & & \\
\hline
\end{tabular}


C. Hooven op Zandgrond.

\begin{tabular}{|c|c|c|c|c|}
\hline \multirow{2}{*}{$\begin{array}{l}\text { Grootte } \\
\text { der hoeve. } \\
\text { H. a. }\end{array}$} & \multirow{2}{*}{$\begin{array}{c}\text { Stichtings- } \\
\text { waarde der } \\
\text { gebouwen. } \\
f\end{array}$} & \multicolumn{2}{|c|}{ BELASTBARE OPBRENGST. } & \multirow{2}{*}{ Toelichting. } \\
\hline & & $\begin{array}{c}\text { Gebouwd. } \\
f\end{array}$ & $\begin{array}{c}\text { Ongebouwd. } \\
f\end{array}$ & \\
\hline 19 & 6300 & 105 & 313 & \multirow{41}{*}{$\begin{array}{l}\text { Gemeenten : Asten, } \\
\text { Bergeijk, Bladel, } \\
\text { Budel, Chaam, } \\
\text { Denrne, Eersel, } \\
\text { Hapert, Hoogeloon, } \\
\text { Lieshout, Mill, Nu- } \\
\text { nen, Someren, A. } \\
\text { Rixtel, Valkens- } \\
\text { waard, Veldhoven } \\
\text { en Zundert. } \\
\\
\text { Tabel A. } 27 \text { hoeven } \\
\text { B. } 29 \\
\text { C. } 42 \\
\text { samen } \\
\text { os hoeven. }\end{array}$} \\
\hline 7 & 6300 & 70 & 130 & \\
\hline 11 & 5950 & 70 & 207 & \\
\hline 9 & 5850 & 25 & 190 & \\
\hline 7 & 5775 & 120 & 174 & \\
\hline 12 & 5600 & 60 & 224 & \\
\hline 8 & 5475 & 100 & $\begin{array}{l}159 \\
184\end{array}$ & \\
\hline $\begin{array}{r}9 \\
10\end{array}$ & $\begin{array}{l}5475 \\
5150\end{array}$ & $\begin{array}{r}70 \\
100\end{array}$ & $\begin{array}{l}184 \\
172\end{array}$ & \\
\hline 11 & 4950 & 100 & 198 & \\
\hline 12 & 4875 & 70 & 225 & \\
\hline 9 & 4800 & 100 & 205 & \\
\hline 21 & 4700 & 140 & 390 & \\
\hline 9 & 4575 & 80 & 199 & \\
\hline 13 & 4575 & 70 & 160 & \\
\hline 7 & 4575 & 60 & 93 & \\
\hline 12 & 4450 & 55 & 239 & \\
\hline 8 & 4350 & 90 & 148 & \\
\hline 11 & 4350 & 60 & 154 & \\
\hline 10 & 4275 & 60 & 183 & \\
\hline 13 & 4250 & 90 & 250 & \\
\hline 9 & 4250 & 70 & 169 & \\
\hline 11 & 4125 & 80 & 279 & \\
\hline 9 & 4100 & 80 & 223 & \\
\hline 9 & 3950 & 100 & 172 & \\
\hline 13 & 3900 & 70 & 294 & \\
\hline 12 & $382 \tilde{5}$ & 100 & 362 & \\
\hline 13 & 3825 & 60 & 217 & \\
\hline 12 & 3775 & 95 & 234 & \\
\hline 10 & 3650 & 90 & 175 & \\
\hline 14 & 3650 & 70 & 200 & \\
\hline 8 & 3650 & 70 & 199 & \\
\hline 10 & 3650 & 60 & 179 & \\
\hline 10 & 35 & 70 & 169 & \\
\hline 24 & 3500 & 80 & 378 & \\
\hline 15 & 3500 & 40 & 159 & \\
\hline 13 & 3450 & 60 & 202 & \\
\hline 10 & 3425 & 80 & 212 & \\
\hline 8 & 3425 & 80 & 158 & \\
\hline 8 & 3425 & 70 & 171 & \\
\hline 9 & 3200 & 70 & 158 & \\
\hline 9 & 3000 & 70 & 165 & \\
\hline $\begin{array}{c}464 \\
\text { gemidd. } 11\end{array}$ & $\begin{array}{r}183425 \\
4367\end{array}$ & $\begin{array}{r}3260 \\
78\end{array}$ & 8672 & \\
\hline
\end{tabular}


De stichtingskosten het punt van uitgang vormende, zijn de gebouwen gerangsehikt naar het afdalend bedrag daarvan.

Zooals bij de bestaande regeling te verwachten was, blijkt dat deze kosten met de belastbare opbrengst "gebouwd" in geenerlei verband staan, maar tevens blijkt dat ook geen verband is te bespeuren tusschen deze belastbare opbrengst en de grootte der hoeve of de betrekkelijke waarde van den grond, blijkende uit de belastbare opbrengst "ongebouwd."

Te vergeefs vraagt men zich af wat dan toch de maatstaf der schatting kan geweest zijn en komt tot geen ander antwoord dan dat blijkbaar de meest uiteenloopende opvattingen hierop van invloed zijn geweest.

Alleen blijkt dat de verhouding van de totale belastbare opbrengst tot de totale stichtingskosten (nieuw) een klein weinig afneemt met de waarde van den grond.

In tabel $A$ is de som der aanslagen $2,1 \mathrm{pCt}$. van de som der stichtingskosten, in tabel B 2 pCt. en in tabel C 1.8 pCt.

Volgens het voorstel zal $3 \frac{1}{2}$ pCt. van de in de $2^{\text {e }}$ kolom vermelde stichtingskosten als belastbaar inkomen worden beschouwd, nadat zal zijn inachtgenomen de waardevermindering door achteruitgang.

De toestand der onderwerpelijke gebouwen laat volkomen toe het aannemen van één midden cijfer voor dezen achteruitgang en dat cijfer stellende op het zeker niet geringe bedrag van ! der stichtingskosten zal moeten blijken of de belastbare opbrengst voldoende lager zoude worden om, rekening houdende met eeue mogelijke, doch zeer vermoedelijk niet belangrijke, verschuiving naar andere gebouwen, eene ontlasting van de landelijke gebouwen te waarborgen of althans waarschijnlijk te maken.

Ter beoordeeling hiervan dienen de tabellen $\mathrm{D}$ en $\mathrm{E}$.

Tabel $\mathrm{D}$ bevat voor de 3 in $\mathrm{A}, \mathrm{B}$ en $\mathrm{C}$ opgegeven rubrieken de totale stichtingskosten van al de gebouwen, verminderd met $\frac{1}{3}$, de hieruit afgeleide belastbare opbrengst ( $3 \frac{1}{2}$ pCt.), de totale thans geldende belastbare opbrengst en het verschil der beide laatste cijfers.

Tabel $E$ bevat geheel dezelfde oijfers als tabel $D$, maar in plaats van al de gebouwen van iedere rubriek bijeen, is hier 
genomen het gemiddelde voor iedere rubriek, van de gebouwen overeenkomende met de 5 hoogste en de 5 laagste der thans geldende aanslagcijfers, benevens die overeenkomende met de 5 thans geldende aanslagcijfers, welke het dichtst komen bij de gemiddelde bestaande aanslagcijfers in de tabellen $\mathrm{A}, \mathrm{B}$ en $\mathrm{C}$ vermeld.

\section{TABEL D.}

Hoeven:
$2 / 3$ van de totale
stichtingsk.

op kleigrond, van gemiddeld 57 H. A. op zavel- en goeden zandgr., v. gemidd. 12 H. A. . . . . . op zandgrond, van gemidd. $11 \mathrm{H}$. A.
A. 249.167
8.721
7.950
f 771 of $c^{\mathrm{a}} 10 \%$ meer
B. $97.933 \quad 3.428$
2.960 f 468 of $c^{n} 16 \%$ meer
C. $122.283 \quad 4.280$
$3.260 \mathrm{f} 1020$ of $\mathrm{c}^{\mathrm{a}} 31 \%$ meer

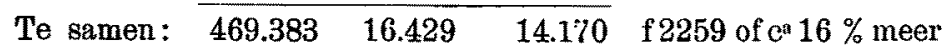

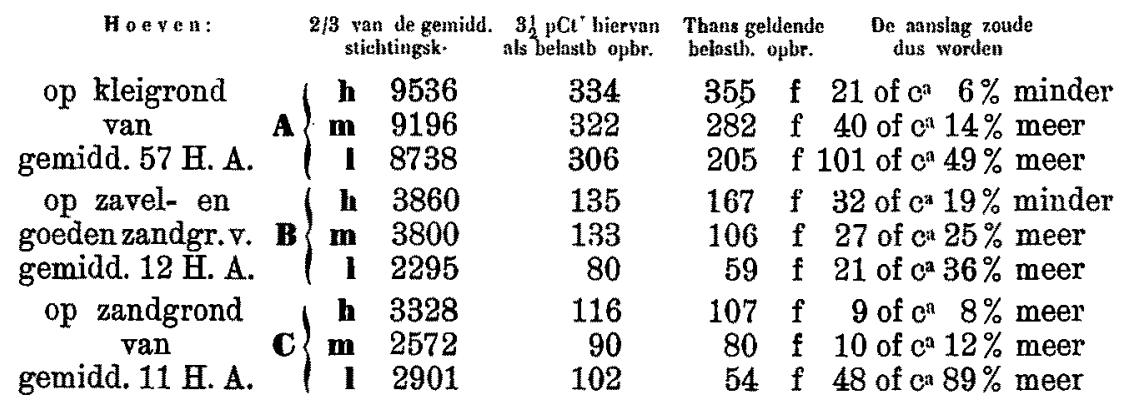

Het totaal der belastbare opbrengst (zie D) zoude dus sterk vermeerderen en alleen wordt eenige vermindering anngetroffen bij twee der combinatiën van enkele der hoogste bestaande aanslageijfers. In alle andere gevallen zoude vermeerdering tot bijna verdubbeling zelfs van den aanslag het gevolg zijn.

Zeker loopen die vermeerderingen sterk uiteen, maar slechts bij uitzondering zijn zij zoo gering dat ook bij de vroeger geopperde mogelijkheid van verschuiving van belastingdruk, de waarschijnlijke vermeerdering van belasting voor de landelijke gebouwen zoude zijn uitgesloten en al zullen ongetwijfeld enkele ook bij deze toepassing van de voorgestelde wijziging worden gebaat, de totale belasting zou zeker aanmerkelijk stijgen. 
De min waardige in slechten toestand verkeerende gebouwen zullen natuurlijk op vermindering de beste kans hebben en veilig mag worden aangenomen dat vele schattingscommissiën den achteruitgang in waarde zeer hoog zullen waardeeren, zoodat terwijl geen algemeene vermindering wordt verkregen de einduitslag in hooge mate afhangt èn van het persoonlijk oordeel der schatters, èn van allerlei toevallige omstandigheden den uiterlijken en tijdelijken staat van het gebouw betreffende, zoodat dus ook de kans op gelijkmatigheid niet groot is. Het is toch de vraag of er niet vele commissiën zullen zijn die voor betrekkelijk nieuwe, in goeden staat van onderhoud verkeerende gebouwen, eene waarde van $\frac{2}{3}$ der stichtingskosten te laag zullen achten.

Wel was, om hieromtrent een voorbeeld te noemen, in het vroeger reeds vermelde wetsontwerp van $1893,60 \mathrm{pCt}$. der stichtingskosten aangenomen als waarde voor andere gewoonlijk niet verkoopbare gebouwen, als sehouwburgen, stationsgebouwen enz., maar daarbij moest rekening worden gehouden met het in die gebouwen uit te oefenen of uitgeoefende bedrijf en de kans van slagen daarin en eveneens met de mogelijkheid dat een dergelijk gebouw oorspronkelijk kon zijn opgericht met een ander doel.

De landelijke gebouwen daarentegen, slechts gebouwd waar zij voor het bedrijf worden noodig geacht, worden steeds tot hetzelfde doel en op nagenoeg geheel dezelfde wijze gebruikt en zullen daarom bij voldoend onderhoud, slechts uiterst langzaam in waarde verminderen.

Al blijkt uit de 3 eerste tabellen dat de stichtingskosten voor deze soort van gebouwen niet op zoo eenvoudige wijze in verband staan met den omvang of de beteekenis van het bedrijf, zeker zijn zij een maatstaf voor de waarde der gebouwen zelf.

De toestand waarin zij zich op een bepaald oogenblik (immers ten tijde der schatting) bevinden, doet daarbij echter niet zooveel ter zake.

Bij onvoldoend onderhoud zijn eerder vernieuwingen noodzakelijk waardoor de tijdelijke besparing zeker wordt opgewogen, maar dan zoude voor eene reeks van jaren de belasting gefixeerd zijn en geen gering bezwaar is er in gelegen, vooral

Econ. 1896. 
ten aanzien der pachters (niet eigenaars) indieu op deze wijze a. h. w. eene premie werd gesteld op onvoldoend onderhoud en onoogelijk aanzien, telkens wanneer de twintigjarige schattingsperiode naderde.

Bij beoordeeling eener zaak is het steeds een gelukkig verschijnsel, wanneer na blootlegging van bevonden bezwaren blijkt, dat door wijzigingen van ondergeschikten aard, daaraan kan worden te gemoet gekomen, zonder aan de leidende gedachte eenige afbreuk te doen.

Zoo ook hier.

Inmers een cijfer, i. c. een verhoudingscijfer, kan veranderd worden, met behoud der overwegingen die het bestaan van de verhouding deden aannemen en waar de stichtingskosten als bruikbare basis erkend, uaar daarentegen de tijdelijke toestand van het gebouw niet vau overwegenden invloed op zijne gebruikswaarde wordt geacht, kan zonder bezwaar de voorgestelde aftrek voor waardevermindering worden gefixeerd.

Dit laatste sluit niet uit dat in sommige gevallen, uitzonderingen, ter beoordeeling der schattingscommissie, kunnen worden toegelaten.

Of bijvoorbeeld een verkleind bedrijf over te groote bestaande gebouwen beschikt of een bestaand gebouw wegens dreigend vergaan van den polder, zeker geen vernieuwing of belangrijke herstellingen meer zal ondergaan, zijn als op feiten berustend, gemakkelijk te beoordeelen gevallen.

Onder fixeering van het bedrag voor waardevermindering, behoeft ook nog niet te worden verstaan dat die aftrek voor alle gebouwen absoluut dezelfde zoude moeten zijn en dus met den toestand waarin een gebouw verkeert volstrekt geen rekening mag worden gehouden.

Alleen eenige beperking van de naar het wetsontwerp al te groote vrijheid aan de commissien gelaten, komt noodzakelijk voor.

Bij de erkende bedoeling van den Minister om aan bestaande bezwaren ten opzichte der landelijke gebouwen te gemoet te komen, schïnt het verkrijgen van overeenstemming zoowel omtrent vermindering van het belastbaar percentage, als omtrent 
meerdere waarborgen voor gelijkmatigheid, bij de verdere behandeling van het wetsontwerp niet zoo moeilijk bereikbaar.

Juiste bepaling der daarbij aan te nemen cijfers vordert, zooals reeds is gezegd, ook wegens het verband met andere gebouwde eigendommen, veel uitvoeriger gegevens dan waarover voor dezen arbeid kan worden beschikt.

Met eene aanduiding der richting waarin de wenschelijke verbetering ligt, moet daarom worden volstaan.

Behoort de toestand waarin het gebouw verkeert, een zekere invloed uit te oefenen op de bepaling der warde, uit Tabel D. blijkt nog bovendien dat bij fixeering èn van den aftrek, èn van het percentage voor alle gebouwen op hetzelfde bedrag, de belastbare opbrengst van de gebouwen op zandgrond, tegenover die op kleigrond, in ongunstiger verhouding zoude komen dan thans het geval is.

Eene verdeeling in klassen naar gelang van den onderhoudstoestand erkent dien invloed en komt tegelijk aan laatstgenoemd bezwaar te gemoet.

Worden bijvoorbeeld alle gebouwen gerangschikt in eeue van 4 klassen als I nieuw of goed-onderhouden, II voldoende onderhouden, III niet voldoende onderhouden en IV bouwvallig en dan voor elke klasse in de wet een vaste aftrek beprald, toenemende bij voorbeeld van 25 pCt. tot 60 pCt. der stichtingskosten, dan is het reeds veel gemakkelijker aan elk gebouw zijne klasse aan te wijzen, dan voor elk afzonderlijk den aftrek te bepalen, dan kan bij verschil van meening de hoofdcommissie op beter grondslag eene beslissing nemen en de zoo noodige gelijkmatigheid is grootendeels verzekerd.

Daar verder, zooals ieder die met beide soorten van gebouwen, althans in de hier bedoelde streken, eenigszins van naderbij bekend is, gereedelijk zal toegeven, in de wijze van onderhoud een hemelsbreed verschil bestaat en even zeldzaam de gebouwen op kleigrond in klasse III zullen thuis behooren, als dit voor gebouwen op zandgrond veelvuldig zal geschieden, wordt het bovenbedoelde bezwaar van wijziging in de onderlinge verhouding belangrijk minder en zal dit minder goede onderhoud, waarvan de algemeene oorzaak is de mindere gegoedheid van den eigenaar in de zandstreken, de billijke aanleiding tot mindere belasting zijn. 
De premie voor allen op minder goed onderhoud wordt door deze regeling wel niet ontgaan, maar haar invloed vermindert omdat tot het plaatsen in eene lagere klasse vrij groot verschil in den innerlijken toestand van het gebouw noodig en daarbij onooglijk aanzien van minder belang is.

Is het geoorloofd uit de beschikbare gegevens eene conclusie te trekken en wordt op grond van het hier aangevoerde ondersteld dat voor de gebouwen der tabellen A. B. en C. de aftrek gemiddeld kwam op respectievelijk $33 \frac{1}{3}$ pCt., 40 pCt. en 45 pCt. van de stichtingskosten, dan blijkt dat, wanneer slechts het belastbaar percentage van $3 \frac{1}{2} \mathrm{pCt}$. werd gebracht op $3 \mathrm{pCt}$., de daar voorkomende belastbare opbrengsten zouden worden:

in tabel A f 7475 of ca. 6 pCt. minder

" " B f 2644" " 10 " 10 " 3027 "

en dat het totaal dezer belastbare opbrengsten zoude verminderen met ca. 7 pCt.

$\mathrm{Bij}$ toepassing derzelfde onderstellingen op tabel $\mathrm{E}$, blijkt dat in deze vermindering alle groepen deelen, behalve juist de kaagst aangeslagenen van de rubrieken vervat in de tabellen $A$ en C. Het is echter zeer goed mogelijk dat deze, tengevolge van ongelijkmatige schattingen, thans in verhouding tot de anderen te weinig betalen.

Uit den aard der zaak kunnen deze ejjfers geen andere waarde hebben, dan als voorbeeld ter verduidelijking van de bedoeling en kan de combinatie tusschen aftrek en percentage nog op allerlei wijze worden afgewisseld.

Berust eene conclusie omtrent de aan te nemen eijfers voorzeker op eenigszins beperkte gegevens, het daaraan voorafgaande geeft voldoenden grond om den ernstigen wensch te uiten dat met nauwkeuriger omschrijving van het deel der stichtingskosten dat voor waarde-verminderiug zal worden afgetrokken, het belastbaar percentage zó6 worde gewijzigd, dat aan de in 


\section{1}

1873 plaats gehad hebbende verzwaring van druk worde te gemoet gekomen en dat allen die op de beslissing invloed kunnen uitoefenen, er naar streven, dat niet door deze herziening de reeds zoo moeilijke toestand, waarin de landbouwer verkeert, nog ongunstiger worde gemaakt.

G. A. M. Groeneveldit.

Breda, November 1895. 